University of Nebraska - Lincoln

DigitalCommons@University of Nebraska - Lincoln

Faculty Publications, Department of Child, Youth, and Family Studies

2020

\title{
Eastern North Carolina Head Start Teachers' personal and professional experiences with healthy eating and physical activity: A qualitative exploration
}

Virginia C. Stage

Lorelei Jones

Jocelyn Bayles

Archana V. Hegde

Dipti Dev

See next page for additional authors

Follow this and additional works at: https://digitalcommons.unl.edu/famconfacpub

Part of the Developmental Psychology Commons, Family, Life Course, and Society Commons, Nutrition Commons, Other Psychology Commons, and the Other Sociology Commons

This Article is brought to you for free and open access by the Child, Youth, and Family Studies, Department of at DigitalCommons@University of Nebraska - Lincoln. It has been accepted for inclusion in Faculty Publications, Department of Child, Youth, and Family Studies by an authorized administrator of DigitalCommons@University of Nebraska - Lincoln. 
Authors

Virginia C. Stage, Lorelei Jones, Jocelyn Bayles, Archana V. Hegde, Dipti Dev, and L. Suzanne Goodell 


\title{
Eastern North Carolina Head Start Teachers' personal and professional experiences with healthy eating and physical activity: A qualitative exploration
}

\author{
Virginia C. Stage,${ }^{1}$ Lorelei Jones, ${ }^{2}$ \\ Jocelyn Bayles, ${ }^{1}$ Archana V. Hegde, ${ }^{3}$ \\ Dipti A. Dev, ${ }^{4}$ and L. Suzanne Goodell ${ }^{5}$
}

\footnotetext{
1 Department of Nutrition Science, East Carolina University, Health Sciences Building 2307B, Greenville, NC 27858, USA

2 Department of Agricultural \& Human Sciences, North Carolina State University, Raleigh, NC, USA

3 Department of Human Development and Family Science, East Carolina University, Greenville, NC, USA

4 Department of Child, Youth, and Family Studies, University of NebraskaLincoln, Lincoln, NE, USA

5 Department of Food, Bioprocessing \& Nutrition Sciences, North Carolina State University, Raleigh, NC, USA

*Corresponding author - Virginia C. Stage, email carrawaystagev@ecu.edu
}

\begin{abstract}
Objective: Explore the interrelationship between teachers' personal and professional socio-ecological structures while examining Head Start (HS) teachers' experiences with (1) trying to eat healthy and engage in physical activity (PA) and (2) promote healthy eating and PA in their classrooms.
\end{abstract}

Published in Public Health Nutrition 24:11 (2020), pp 3460-3476.

doi:10.1017/S1368980020003687

Copyright (C) 2020 Virginia C. Stage, Lorelei Jones, Jocelyn Bayles, Archana V. Hegde, Dipti A. Dev, and L. Suzanne Goodell. Published by Cambridge University Press on behalf of The Nutrition Society. Used by permission.

Submitted 5 February 2020; revised 25 August 2020; accepted 16 September 2020; published 16 November 2020. 
Design: In-depth semi-structured interviews were collected from March through June 2017. Researchers designed the data collection and analysis methods using a phenomenological approach. All interviews were recorded using digital audio and transcribed verbatim.

Setting: Seven HS centers in two rural eastern North Carolina counties.

Participants: Teachers ( $n$ 15) who had recently participated in a healthy eating and physical activity intervention. Participants were $100 \%$ female, an average age of 43 years (SD 9.6) and primarily Black/African American (93.3\%).

Results: Eighteen primary themes were identified providing unique insight into individual, social and environmental determinants that may influence teachers' personal health behaviors and professional health promotion practices. Findings indicated that teachers want to improve health behaviors personally (individual/ family health) and professionally (children/families served); however, barriers exist at all levels impacting their ability to improve their own health and facilitate positive behaviors among the children/families they serve. Many teachers observed connections between their personal and professional experiences, but not beyond the individual level.

Conclusions: Study findings highlight the importance of considering and emphasizing the potential relationship between personal and professional determinants of health when working with early childhood teachers. Findings from this study may be useful for informing the development, implementation and evaluation of future health promotion interventions using teachers as implementers.

Keywords: Head Start, Preschool, Teachers, Social ecological theory, Healthy eating, Physical activity

Head Start (HS) is the largest federally funded early childhood education program in the USA, serving low-income, limited resource, 3-5-year-old children and their families. ${ }^{1} \mathrm{HS}$ reaches more than 1 million children each year making it an ideal setting for implementing obesity prevention programming among children and families who are at increased risk. ${ }^{2,3}$ Prior literature has suggested children enrolled in HS are more likely to be obese compared with the general population of preschool-aged children. ${ }^{4}$ Additionally, a recent study reported that, compared with non-HS preschoolers, 3-year-old children who entered HS with an unhealthy weight status were significantly more likely to enter kindergarten at 5 years of age with a healthy BMI. 5

HS began in 1965, when obesity was not common among children, but federal founders of the program understood the importance of children's physical health and its influence on their social competence and capacity to learn. As a result, policies addressing prevention of 
overweight/obesity were embedded within the HS infrastructure. ${ }^{6}$ While the Program Performance Standards (PPS) and federal regulations governing HS programs focus on core developmental domains such as cognitive and socioemotional development, HS programs are also required to provide programming focused on health and offer meals, snacks and nutrition education. ${ }^{1}$ It has been theorized that this comprehensive approach to promoting school readiness and health is the reason for observed positive effects on nutrition and physical activity (PA) practices among young children in HS environments. ${ }^{7-9}$ Responsible for implementing many of the childhood obesity prevention-related PPS, HS teachers are key partners for expanding efforts to encourage healthy lifestyles among children and families. ${ }^{10,11}$ Unfortunately, while teachers express the importance of practicing healthy eating and PA behaviors for themselves and the children and families they serve, determinants at the individual, social, economic and environmental levels may impact teachers' efforts to change their own health behaviors and promote healthy eating and PA in their classrooms. ${ }^{12,13}$

Due to the large amount of time children spend at school, teachers' impact on children's healthy eating and PA levels may be as influential as children's parents. ${ }^{14,15}$ Unfortunately, early childhood teachers may not eat healthy foods and exercise in their personal lives ${ }^{2,14}$ calling into question teachers' ability to effectively role model positive health behaviors to the children and families they serve. High levels of overweight and obesity ( $>70 \%$ ) exist among HS teachers. ${ }^{2,16}$ Potentially related intake among early childhood teachers includes low intakes of healthy foods such as fruits and vegetables, high intake of unhealthy foods and beverages (e.g. sugar sweetened beverages, fried foods $)^{2,16}$ and high levels of sedentary behaviors ( 4 and $8.6 \mathrm{~h} / \mathrm{d}$ ). ${ }^{17,18}$ Some researchers have theorized when teachers realize the importance of their own health behaviors and are provided with appropriate training, they may be better able to successfully model and promote positive health behaviors in their classrooms ${ }^{19,20}$. For example, a teacher who is working to improve their own personal eating behaviors may be more likely to role model healthy eating for children in their care. ${ }^{21}$ However, other researchers have questioned this theory stating an improvement in teachers' knowledge may not necessarily translate into improved teaching practices. ${ }^{22,23}$ 
Teachers who implement best practices in the classroom, such as enthusiastically role modelling healthy eating, providing nutrition education and avoiding food-based rewards, can help children choose healthier foods when the foods served are of high nutritional value. ${ }^{24}$ However, contextual factors may support or work against teachers' ability to implement these best practices. At the individual level, teachers' personal health behavior and status, ${ }^{16,24}$ knowledge and attitudes ${ }^{13,22,25-28}$ and cultural background ${ }^{23,29}$ may influence teaching practices. At the social level, families may serve as a significant barrier ${ }^{30-34}$ leaving some teachers to feel frustrated and discouraged when parents do not support efforts to promote the healthy behaviors learned at school in the home environment. Finally, at the environmental level, policies, staff knowledge and training opportunities, limited time, material resources and funding can also work in support or against teacher efforts to implement best practice in their classrooms. ${ }^{13,23,35-37}$

Childhood obesity prevention programs often rely on early childhood teachers to implement the program because they are responsible for teaching nutrition education curricula and encouraging healthy eating among children across diverse learning environments. ${ }^{2}$ Teachers who place emphasis on their own personal health and PA levels may be more likely to promote those same behaviors in their classroom, thus positively affecting child health, ${ }^{20,38}$ but more research is needed to explore the specific determinants that influence teachers' personal and professional healthy eating and PA behaviors. To date, several studies have separately explored factors that may impact teachers' personal ${ }^{14,16,39}$ and professional ${ }^{12,13,40,41}$ health behaviors at individual, social and environmental levels. However, to the author's knowledge, only one quantitative study has come close to exploring teachers' personal and professional experiences simultaneously. ${ }^{26}$ Further, most qualitative studies are focused on identifying factors influencing the implementation of specific classroom practices, e.g. mealtime, with few studies focusing on understanding the role of the broader context such as personal healthy eating belief and its influence on classroom practices. ${ }^{12,14,26,41}$ Taken together, more research is needed to understand the specific determinants that influence teachers' personal and professional experiences with healthy eating and physical activity. Exploring these 
factors simultaneously is also needed in order to support an understanding of potential interrelationships between the two socio-ecological structures. Therefore, the purpose of this study was to qualitatively explore teachers' personal and professional socio-ecological structures while examining HS teachers' experiences with (1) trying to eat healthy and engage in PA and (2) promote healthy eating and PA in their classrooms.

To provide context for exploring these factors, partners from two North Carolina (NC)-based HS organizations collaborated to implement the evidence-based, hands-on intervention, Families Eating Smart and Moving More (FESMM), with the goal of educating HS teachers to improve their personal healthy eating and PA behaviors. FESMM was developed by NC Cooperative Extension at NC State University and the NC Division of Public Health and is an evidencebased, hands-on intervention targeting the four impact goals of the Expanded Food and Nutrition Education Program (EFNEP): (1) improve diet quality and PA of the family; (2) improve food resource management skills; (3) improve home food safety practices and (4) decrease food insecurity. Interactive nutrition education sessions were developed based on a community needs assessment of current diet and PA behaviors, food resource management skills, food safety practices and food security practices among low-income, lowresource adults living in NC..$^{2}$ Each of the six 45 -min lessons included food experiences, tastings, demonstrations and opportunities to practice simple PA and hands-on activities to engage participants and increase targeted skills.

\section{Methods}

\section{Research design}

Researchers used in-depth, semi-structured interviews to examine NC HS teachers' personal and professional experiences with healthy eating and PA. Researchers designed data collection and analysis methods using a phenomenological approach - a qualitative method that studies common experiences among a group of individuals. ${ }^{43,44}$ All study materials were approved by East Carolina University's Institutional Review Board. 


\section{Sampling and participants}

Researchers utilized purposive criterion sampling to identify eligible teachers across seven centers in two rural eastern NC counties. This method of sampling ensured the creation of a homogenous sample of participants who all experienced the same phenomenon. ${ }^{43-45}$ Study inclusion criteria required teachers to be 18 years or older, employed by a NC-based HS program located in one of two counties in eastern NC, and have completed the EFNEP FESMM curriculum, to ensure teacher participants had prior experience with trying to improve their personal healthy eating and PA behaviors. See Table 1 for additional details.

\section{Recruitment}

At the beginning of the FESMM curriculum, teachers were informed about the opportunity to participate in in-depth telephone interviews that would occur at the end of the program. Researchers recruited eligible teachers to participate in the interviews by attending the last FESMM lesson, distributing flyers and directly emailing teachers within each HS center. Researchers also asked partnering HS Health/ Nutrition Coordinators to distribute information about the study to teachers in their respective centers.

\section{Data collection and protocols}

Researchers developed a semi-structured interview guide featuring a verbal script and interview questions with probes (Table 2). Three trained researchers conducted telephone interviews between March and June 2017. Prior to the beginning of data collection, interviewers were trained in human ethics and qualitative research methods using the Goodell 5-Phase Protocol for training interviewers. ${ }^{46}$ This process also served to pilot test the interview guide. Teachers who expressed interest in participating in an interview were contacted via email to schedule an interview time and share a copy of the consent form for review. At the beginning of the interview, the interviewer read the consent form to the participant and obtained verbal consent. The interviewer then signed a hard copy of the consent form on behalf of the participant and returned a scanned copy of the signed document to the participant via email (or mail if requested). 
Table 1 Eating smart and moving more 6-lesson series content*

\begin{tabular}{|c|c|c|}
\hline Lesson title & Lesson objectives & Key messages \\
\hline Fix it & $\begin{array}{l}\text { 1) Identify simple food safety practices at home } \\
\text { or away. } \\
\text { 2) Identify foods that should be avoided by } \\
\text { pregnant and breastfeeding women and } \\
\text { children under the age of } 5 \text { years. } \\
\text { 3) Identify strategies to keep children safe in } \\
\text { the kitchen. } \\
\text { 4) Set one food safety goal for their family. }\end{array}$ & $\begin{array}{l}\text { 1) CLEAN hands and surfaces thoroughly. } \\
\text { Sanitize kitchen surfaces after cleaning. } \\
\text { 2) SEPARATE, don't cross contaminate. } \\
\text { 3) COOK foods to proper temperature. } \\
\text { 4) CHILL refrigerate foods promptly. }\end{array}$ \\
\hline Shop the best for less & $\begin{array}{l}\text { 1) Identify information found on nutrition label. } \\
\text { 2) Use the nutrition label to identify whole } \\
\text { grain products. } \\
\text { 3) Use labels to choose low-fat and low-sodium } \\
\text { foods. }\end{array}$ & $\begin{array}{l}\text { 1) Use labels to compare foods. } \\
\text { 2) Use labels to help control portions. } \\
\text { 3) Use labels to idea whole-grain products. }\end{array}$ \\
\hline $\begin{array}{l}\text { Shop for value - check } \\
\text { the facts }\end{array}$ & $\begin{array}{l}\text { 1) Use a shopping list. } \\
\text { 2) Read unit pricing labels to select the best } \\
\text { buy. } \\
\text { 3) Use in-store ads, newspaper ads, and } \\
\text { coupons to get the most for their money. }\end{array}$ & $\begin{array}{l}\text { 1) Shop with a list to make sure you get the } \\
\text { things you need. } \\
\text { 2) Use in-store ads, newspaper ads, coupons, } \\
\text { and unit pricing to get the most of your } \\
\text { money. }\end{array}$ \\
\hline $\begin{array}{l}\text { Plan: know what's for } \\
\text { dinner }\end{array}$ & $\begin{array}{l}\text { 1) Create a family favorite list to help with meal } \\
\text { planning. } \\
\text { 2) Plan a one-week dinner menu. } \\
\text { 3) Develop a grocery list for the planned menu. }\end{array}$ & $\begin{array}{l}\text { 1) Take a few minutes each week to plan } \\
\text { "what's for dinner". It will save time in the } \\
\text { long run. } \\
\text { 2) Plan weekly meals to save money. } \\
\text { 3) Plan meals to help you and your family eat } \\
\text { smart. }\end{array}$ \\
\hline $\begin{array}{l}\text { Choosing more fruits \& } \\
\text { vegetables }\end{array}$ & $\begin{array}{l}\text { 1) Identify three ways to include a variety of } \\
\text { fruits and vegetables in their diet including } \\
\text { green, red, and orange/yellow. } \\
\text { 2) Identify strategies to help save money on FV. } \\
\text { 3) Identify wide variety of fresh, frozen, and } \\
\text { canned FV available to them and their } \\
\text { families. } \\
\text { 4) Set one goal to increase FV in their family } \\
\text { meals. }\end{array}$ & $\begin{array}{l}\text { 1) Eat FV at meals and for snacks each day. } \\
\text { 2) Eat a variety of colors of FV each day. } \\
\text { 3) Make half your plate FV. }\end{array}$ \\
\hline $\begin{array}{l}\text { Choosing to move } \\
\text { more throughout } \\
\text { the day }\end{array}$ & $\begin{array}{l}\text { 1) State importance of PA for all ages. } \\
\text { 2) Identify recommended PA activity minutes } \\
\text { for appropriate age group. } \\
\text { 3) Identify health benefits of regular PA. } \\
\text { 4) Incorporate PA into their daily lives. }\end{array}$ & $\begin{array}{l}\text { 1) Choose to be active. } \\
\text { 2) PA can be done every day, everywhere, at } \\
\text { any time and place. } \\
\text { 3) Setting small goals to gradually increase PA } \\
\text { is best. }\end{array}$ \\
\hline
\end{tabular}

* Lessons where 30-45 min in length and focused on engaging teachers in food experiences, tastings, opportunities to practice simple physical activity, and hands-on activities to engage participants. The series focused primarily on improving teacher's personal health behaviors and not professional development on how to teach children or families about making healthy eating and physical activity behavior changes. 
Table 2 Primary in-depth interview questions for Head Start Teachers participating in data collection on teacher's" experience with improving their personal healthy eating and physical activity and promoting healthy eating and physical activity in their classroom

\section{Personal experiences}

What does being a healthy person mean to you?

Can you describe a time when you tried to make healthier food choices?

What barriers have you faced when trying to make healthier food choices?

What facilitators have you experienced when trying to make healthier food choices?

What motivates you (or would motivate you) to make healthier food choices?

\section{Professional Experiences}

What do you think your role is in teaching children about healthy eating and physical activity? Families?*

What has been your experience with promoting healthy eating and physical activity to children in your classroom? Families?

What barriers have you experienced when trying to promote healthy eating and physical activity to children in your classroom? Families?

What facilitators have you experienced when trying to promote healthy eating and physical activity to children in your classroom? Families?

What would you say motivates you to promote healthy eating and physical activity to children in your classroom? Families?

\section{Experience with Eating Smart, Moving More}

How has your experience with the Eating Smart and Moving More workshop series affected your job as an early childhood teacher?

* Interviewers were trained to probe further if a participant did not fully answer a question (e.g. addressed their role in teaching about healthy eating, but not physical activity).

During the 45-6o min interviews, researchers encouraged teachers to share their personal experiences/stories related to improving their personal health and their past experiences with promoting healthy eating and PA among children and families. Researchers recorded all interviews in digital audio format. An independent transcription service transcribed the recordings verbatim. As data were collected, the principal investigator engaged in preliminary open coding in order to track saturation. Data collection continued until saturation was achieved. ${ }^{47}$ A minimum of ten interviews has previously been cited as appropriate within phenomenological study designs where saturation is achieved. 44,45

Researchers utilized several techniques to ensure trustworthiness. Strategies included maintaining detailed notes and memos for each interview, audio recordings, peer debriefing, member checking, bracketing to identify potential researcher bias and triangulation of data 
with HS partners..$^{4}$ To triangulate findings, final themes were sent to each participating teacher for review. Teachers were asked to review and reflect on the accuracy of a summary of their individual interview and major identified themes. While only three teachers responded to the request, all reported the summary and themes provided accurately reflected their perspectives and experiences. 45,48

\section{Data analysis}

The Statistical Package for Social Science (SPSS) 22.0 was used to analyze descriptive statistics for basic demographic information. Researchers utilized phenomenological methods to guide data analysis following Moustakas's structured method for inductive data analysis. ${ }^{43}$ The principal investigator and one research assistant read all transcribed interviews twice to immerse themselves in the dataset. The team read the transcripts a third time focusing on memoing, development of a coding template and identification of key themes. ${ }^{43}$ Researchers followed four steps for the in-depth analysis. First, the analysis team developed a list of significant statements about the participants' experience with the program (Step 1). Next, the team reduced and eliminated statements that did not represent details necessary for understanding the participant experiences (Step 2). Codes were clustered and reduced into eighteen themes representing teachers' experiences with the phenomenon of interest (Step 3). Finally, the principal investigator confirmed the presence of each theme by rereading complete transcripts to ensure identified themes accurately represented participants' words (Step 4). Themes were used to describe "what" was experienced and "how" it was experienced. Written descriptions were used to construct the overall "essence" of teachers' experiences. ${ }^{43,44}$

\section{Results}

\section{Participants}

Researchers completed fifteen in-depth interviews with HS teachers. Saturation was achieved at nine interviews; however, data collection continued until fifteen to ensure no new information would be 
obtained with additional interviews. Teachers were $100 \%$ female, an average age of 43 years (SD 9.6) and Black/African American (93.3 \%) or Latino (6.7\%). Teachers had 9.9 years (SD 8.1) of teaching experience. A total of $26.7 \%$ of teachers reported they had a 2 year Associates degree and $40 \%$ a 4 year degree in Early Childhood Development.

\section{In-depth interview results}

Researchers identified eighteen primary themes related to teachers' experiences when trying to improve their personal health behaviors and professionally promote healthy eating and PA in their classrooms (Table 3). To better understand the dynamic interrelationships between individual, social and environmental influences on teacher behavior, researchers inductively organized themes and subthemes under teachers' personal and professional experiences by the Theory of Social Ecology constructs. ${ }^{49}$ The theory identifies four influences related to behavior including Human Aggregate (e.g. sociocultural characteristics of individuals); Social Climate (e.g. the supportiveness of a social setting); Organizational Setting (e.g. worksite, school) and Physical Setting (e.g. weather and built environments) (Table 3). Finally, researchers explored the interrelationship between teachers' personal and professional social ecological structures as a separate emergent theme. Figure 1 visually represents the identified themes within the theoretical model.

\section{Teachers' personal experiences with healthy eating and physical activity}

Human aggregate

Teachers described sociocultural characteristics that influenced their healthy eating and PA behaviors including their Perception of Personal Health, Personal Motivators and Personal Barriers. When asked to describe what being "healthy" meant to them, teachers described personal health issues (e.g. blood pressure, obesity), physical feelings related to health (e.g. pain, weight status) and/or their philosophy of being healthy (e.g. "healthy does not mean being a size four"). The majority of teachers expressed that it was their responsibility to take care of their own health and recognized the importance of learning to lead a healthy lifestyle to prevent disease and/or extend their lifespan. 
Table 3 Supportive Head Start Teacher quotations for themes and sub-themes aligned with the theory of social ecology constructs $(n=15)$

SEM constructs Themes Subthemes Quotes

Personal experiences with healthy eating and physical activity behaviors

Human aggregate

Perception of personal health

aning of "healthy"

Personal accountability

Personal motivators

Positive health outcomes

Family Health Concerns

Personal barriers Fatigue

Socioeconomic status (e.g. money, time)

Time

Social climate

Perceived Social

Facilitators

Perceived Social Barriers

Organizational setting
Community support Health insurance
"Things" (e.g. social media, exercise classes)
Motivation to learn

"[l just want to be] at a weight where I can move my body. I think we put a lot of emphasis on weight. And it's not really what you weigh. It's what you feel comfortable with, what you can move around and not feel like you're exhausted and going to die. I'm sorry, I don't want to be a size eight. But I would be happy being a size 12."

"We can choose to eat healthier - stroke and diabetes and heart trouble because we eat what we want instead of eating what we need."

"I think learning is a motivation in itself for me. I feel the more I know, the more I grow. The more I care, the more I share. I don't know of another way to explain it. I get my motivation from learning. I feel you're never too old to learn. I try to get all the knowledge and wisdom I can get from other people sharing their experiences and their knowledge of whatever the situation might be."

"When I see that I lost maybe two inches or two pounds, it motivates me to even walk more."

"Well, I have four children. And I don't want to die from a heart attack. I don't want to have diabetes. So, in order for me to do that, I have to eat healthy. And I have to prevent those things from occurring."

"Sometimes when I get home, I'm just too tired from running with the children and playing with them all day. When I get home, I'm too tired to do it on my own."

"Money for purchasing healthier food [has] been my barrier cause it's so expensive. And I can't spend all my money just on this, [what are we] going to eat later? I do try to have healthier stuff here, but at the same time, we got to make sure we got something to eat the rest of the month. There's four of us."

"One of the barriers is working long hours. If I'm working till 6:00 pm in the evening and I have to go home and fix dinner for the kids, either I eat late, or I don't eat at all. It depends on how tired I am. I may not calculate my portions and eat too much."

"People" (e.g. family, "She [my daughter] is always trying to get us to eat physicians) healthier."

"We have a professional [online] wellness group at my church. What we do is we post what we had for that day and we try to, you know, encourage each other to eat healthy foods. We look at each other's posts and we say, well ok that's something new that I can try to cook, and it's healthy."

"Having family gatherings, at work when your co-workers come to you and they want to offer you pizza and cake and tuff. We have little potluck at work - just those temptation things. Or they'll bring some donuts to work. Or something will bring some cookies or fried chicken. Those are barriers for me."

"My insurance company keeps hounding me about wellness, Blue Cross Blue Shield. I just renewed my insurance for the year, and they are saying that we have to walk at least 30 minutes a day, drink at least 8 bottles of water a day. You know they are trying to promote [health], I guess by keeping our insurance low, so that has motivated me to keep my insurance low." 
Table 3 (continued)

\begin{tabular}{|c|c|c|c|}
\hline SEM constructs & Themes & Subthemes & Quotes \\
\hline & & $\begin{array}{r}\text { Community } \\
\text { churches }\end{array}$ & $\begin{array}{l}\text { "We motivate each other in eating healthy, as well as my } \\
\text { church family due to that wellness group. It has taught me } \\
\text { to eat healthy because it's all around me, everywhere I go } \\
\text { home, work, church, so those are some things that have } \\
\text { helped." }\end{array}$ \\
\hline & Policy \& regulations & School meals & $\begin{array}{l}\text { "We can't bring our own food at work. We have to eat what } \\
\text { is served to us. And I just don't like it. I'm not going to eat } \\
\text { just anything. So, a lot of times, I might go hungry." } \\
\text { "I tend to overeat [when I get home] because we don't have } \\
\text { very good choices at work." }\end{array}$ \\
\hline \multirow[t]{3}{*}{ Physical setting } & $\begin{array}{l}\text { Environmental } \\
\text { supports }\end{array}$ & $\begin{array}{l}\text { Access to resources } \\
\& \text { facilities }\end{array}$ & $\begin{array}{l}\text { "I tried to increase my physical activity by walking. I started } \\
\text { off walking. But I found that walking by myself didn't } \\
\text { work so well. So, what I did to substitute my waking for } \\
30 \text { minutes, my kids got a Wii stick a couple of years back. } \\
\text { So, I either do something on the Wii stick. Or I'll do } 30 \\
\text { minutes of the yoga. And the reason why I said that works } \\
\text { better for me because I don't have to drive anywhere to } \\
\text { go to the track. I'm at home. I can still watch my children. } \\
\text { I don't have to get no one to watch them." }\end{array}$ \\
\hline & \multirow[t]{2}{*}{$\begin{array}{l}\text { Environmental } \\
\text { barriers }\end{array}$} & $\begin{array}{l}\text { Daylight savings } \\
\text { time }\end{array}$ & $\begin{array}{l}\text { "Some of it has been the weather. But I think all that will } \\
\text { improve now that it's going to start getting darker later. } \\
\text { Then I can go out about 5:00 and go walk around and it } \\
\text { not get dark so fast." }\end{array}$ \\
\hline & & $\begin{array}{l}\text { Weather (e.g. very } \\
\text { cold or hot } \\
\text { temperatures, } \\
\text { rain) }\end{array}$ & $\begin{array}{l}\text { "I usually walk. But with the weather so up and down and } \\
\text { cold, I don't get out there when it's too cold." }\end{array}$ \\
\hline
\end{tabular}

\section{Professional experiences with advocating for healthy eating and physical activity behaviors}

Human aggregate

Motivators to

promoting

positive health

behaviors

Perception of role to promote positive health behaviors
Genuine desire for children/parents to be healthy

Feelings of making a difference

Seeing them enjoy healthy food

Responsibility to teach

Child as agent of change
"I want the children to be healthy. And if they're not eating properly, they're going to be less healthy. I want them to be healthy. And they can be healthy by doing exercise and eating right. There's only so much we can do in school because we don't know what they're doing at home. I can just do what I can on my part at school."

"I [have] actually seen where my parents have had friends come over while I was in their home and asked their friends to participate in the activities or the exercises that we were doing. I thought that was just awesome. That showed me that I was teaching them something. And they were taking what I taught them and giving it to the next person. I thought that was excellent."

"Just seeing them enjoy healthy food [motivates me]. A lot of them like apples; a lot of them like carrots; a lot of them like broccoli. And there are those that don't like broccoli - but to see them eat good stuff instead of eating the bad stuff like candy and junk food, to me that is so much better that it really motivates me."

"I have to practice what I preach, so I have to try some of these foods that I don't like, I have to try these foods before I try to get the children to eat them,"

"My role is an important [one] to teach the families because once the children leave school, it's very important that they carry, that the families, like the parents, teach them as well at home about eating healthy and providing them with good health and nutritional choices for breakfast, lunches, and dinner."

"And I encourage everybody to try the granola bar. And if they like it, when we get back in the classroom, I can say when you go grocery shopping with your mother, ask your mom to buy you some granola bars." 
Table 3 (continued)

\begin{tabular}{|c|c|c|c|}
\hline SEM constructs & Themes & Subthemes & Quotes \\
\hline \multirow[t]{6}{*}{ Social climate } & \multirow[t]{2}{*}{$\begin{array}{l}\text { Child-related } \\
\text { Factors }\end{array}$} & Food preferences & $\begin{array}{l}\text { "I guess the only real barrier would be actually getting the } \\
\text { children to try it. To get them to try it, I'll try it. We're } \\
\text { going to take a monster bite, just one, just to try it. And if } \\
\text { you don't like it, you don't have to eat it anymore. But if } \\
\text { you like it, I want you to enjoy the rest of the whole snack. } \\
\text { That's what I do in class." }\end{array}$ \\
\hline & & $\begin{array}{l}\text { Physical activity } \\
\text { preferences }\end{array}$ & $\begin{array}{l}\text { "[The children will] say they're tired. Before we finish [our } \\
\text { physical activity], they'll say they're tired and want to } \\
\text { sit down. I try to encourage them to try to do it a little } \\
\text { bit longer, but most of them will say they're tired. And } \\
\text { those are mostly if they're really kind of overweight or } \\
\text { something like that. They're not used to doing exercise." }\end{array}$ \\
\hline & \multirow[t]{4}{*}{$\begin{array}{l}\text { Parent-related } \\
\text { Factors }\end{array}$} & Engagement & $\begin{array}{l}\text { "When I try to have the families come in to do one-on-one, } \\
\text { they don't show up. We try to do a parent meeting. } \\
\text { And I send home what we're going to discuss and wear } \\
\text { comfortable clothes cause we're going to work out with } \\
\text { the children, they don't show up like they should - so } \\
\text { poor participation from the parents." }\end{array}$ \\
\hline & & "Set in their ways" & $\begin{array}{l}\text { "I would have to say that parents are more, I don't know, I } \\
\text { guess set in their ways when it comes to eating certain } \\
\text { types of foods, and it is definitely hard to get them to try } \\
\text { to try different things or try healthier foods if they're once } \\
\text { again, not used to it or they don't like the taste of it." }\end{array}$ \\
\hline & & Communication & $\begin{array}{l}\text { "We don't see them very often. We can only send things } \\
\text { home like paperwork. But we aren't sure if they are } \\
\text { actually reading it." }\end{array}$ \\
\hline & & $\begin{array}{l}\text { Socioeconomic } \\
\text { Barriers }\end{array}$ & $\begin{array}{l}\text { "The fact that they can get a double cheeseburger for a } \\
\$ 1.00 \text { versus actually going home and cooking. A lot of } \\
\text { them say that they're tired from getting off work, say they } \\
\text { don't have time to cook, so they run to McDonald's and } \\
\text { we have a lot of kids that are addicted to the Arch. So, fast } \\
\text { food over family time is really, it's a real problem." }\end{array}$ \\
\hline \multirow[t]{4}{*}{$\begin{array}{l}\text { Organizational } \\
\text { setting }\end{array}$} & $\begin{array}{l}\text { Administrative } \\
\text { support }\end{array}$ & $\begin{array}{l}\text { Supportive } \\
\text { administrators }\end{array}$ & $\begin{array}{l}\text { "Our center really focuses on healthy eating, so that helps } \\
\text { out a lot. They serve mostly healthy eating. They focus } \\
\text { on [physical activity] as well. They encourage us to play } \\
\text { with the children, try to keep them busy as far as doing } \\
\text { some activity that will help out with the exercise. They } \\
\text { encourage us to do that, whether it is playing a game, } \\
\text { jump rope or hide-and-seek to encourage the exercise } \\
\text { and activity." }\end{array}$ \\
\hline & \multirow[t]{2}{*}{ Community support } & $\begin{array}{l}\text { Community health } \\
\text { professionals }\end{array}$ & $\begin{array}{l}\text { "I've actually had someone from WIC come to the classroom } \\
\text { and talked to the children about the importance of } \\
\text { drinking milk and your serving sizes and what'd you need } \\
\text { to get in your body." }\end{array}$ \\
\hline & & Donations & $\begin{array}{l}\text { "We go to the farmers market, they donate things. Going to } \\
\text { the local farmers market really helps." }\end{array}$ \\
\hline & Policy \& regulations & School meals & $\begin{array}{l}\text { "We should introduce the children to a variety of vegetables. } \\
\text { The menu is repetitious. Every week its basically the same } \\
\text { thing. So, they're not getting to experience a variety of } \\
\text { food. And I don't really like a lot of the food. I'll put it on } \\
\text { my plate, but I may just not eat it." }\end{array}$ \\
\hline \multirow[t]{2}{*}{ Physical setting } & \multirow[t]{2}{*}{$\begin{array}{l}\text { Environmental } \\
\text { supports and } \\
\text { barriers }\end{array}$} & Weather & $\begin{array}{l}\text { "We go out every day at least an hour. If the weather is bad } \\
\text { or if it rains, the main thing is if the weather is bad, there's } \\
\text { a storm coming in, we'll be inside." }\end{array}$ \\
\hline & & $\begin{array}{l}\text { Access to resources } \\
\& \text { facilities }\end{array}$ & $\begin{array}{l}\text { "And with the physical activity, our playground it not really } \\
\text { set up like maybe other playgrounds would. There are } \\
\text { very limited things that we have out there to actually } \\
\text { do promote the physical activity. We don't have bicycles } \\
\text { there. Our playground is just very bare. There's not really } \\
\text { too much we can do besides play ball or baseball, kickball } \\
\text { or something. But as far as swings and slides, they don't } \\
\text { have that." }\end{array}$ \\
\hline
\end{tabular}


Table 3 (continued)

\begin{tabular}{lcc} 
SEM constructs & Subthemes & Quotes \\
\hline & Parent barriers & "Physical activities - some of them complained it is too hot \\
in the evening. They have to especially get a decent place \\
where they can ask to work out as to just - as to working \\
out at your own house, in your own yard, in activities with \\
your child outside in your own yard."
\end{tabular}

Teacher connection between personal \& professional experiences with healthy eating and physical activity behaviors

Human aggregate Making the Energy for my connection
Energy for my
students

Empathizing for better health Helpless to help
"I try to eat things that help me have energy for my students."

"I would say I have seen [the effect of poor health] in my own family. Children that are obese, some family members, adults, that are overweight due to eating unhealthy foods. It motivates me to teach my students to each healthy because I don't want to see them in that type of situation."

"I can't so much change what these other children are doing in their house. I can speak to parents. At the end of the day, I'm not cooking for them."

Teachers generally acknowledged the need to improve their own health behaviors and were motivated by opportunities to learn how. Several teachers stated center-level activities intended to teach children and families about positive health behaviors were also opportunities for them to learn about healthy lifestyle choices. Most teachers also frequently commented on improving their health to ensure that they could live a long life and/or to ensure they could "be there" for their families. One teacher stated, "I want to be able to see my babies have babies and be able to play with those babies. If I continue the path that I'm on, I'm not going to be able to see them grow up."

Despite describing numerous motivators, teachers also recognized personal barriers to making healthy choices such as fatigue, socioeconomic factors and limited time. Some teachers described being too tired to make healthy choices, such as preparing a healthy meal or engaging in PA after work. Teachers described facing similar socioeconomic barriers as their HS families, frequently stating that being low income themselves influenced their ability to purchase fruits and vegetables and afford adequate childcare that might support their ability to be more physically active after work. Teachers also described how their busy schedules limited their time to prepare meals at home and/ or have sit down family meals often leading to a reliance on fast food. 


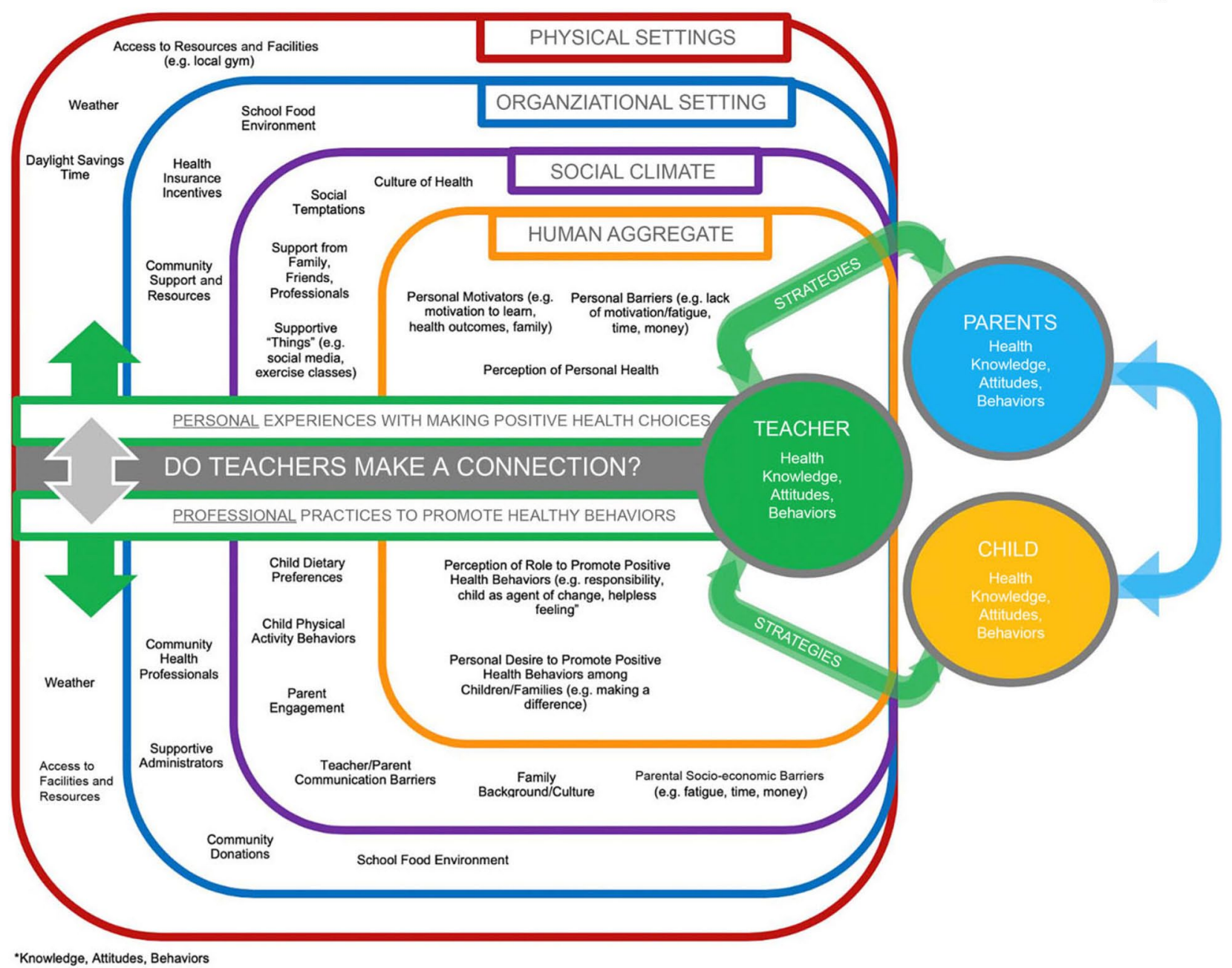

Figure 1 Theoretical model presenting relationships between Head Start teachers' (n 15) individual, social, and environmental influences

\section{Social climate}

Social characteristics that reportedly affected teachers' personal healthy eating and PA behaviors were Perceived Social Facilitators and Perceived Social Barriers. Teachers described "people" as supportive of their ability to make positive personal health choices including family members, friends, physicians, fitness instructors and/or their church community. Teachers also described "things" they considered supportive of their personal healthy eating and PA behaviors including healthfocused discussion boards/ social media with friends (particularly 
those that share healthy recipes), exercise videos, listening to music during exercise, fun exercise classes and educational opportunities to learn about healthy eating and PA. Social barriers were less frequently described but often centered on temptations to eat unhealthy foods at home and/or social functions at church.

\section{Organizational setting}

Organizational characteristics that impacted teachers' personal dietary and PA behaviors were identified as Community Support and Policy \& Regulations. Teachers mentioned community support, such as health insurance wellness initiatives and community churches, as helpful towards helping them making positive health choices. Several teachers discussed the importance of a culture of health in their everyday life to provide support and encouragement for making healthy choices. Policy and regulations were also reported as influential on teachers' health behaviors, particularly those related to the Child and Adult Care Food Program (CACFP) and the HS PPS that require teachers to eat what is served to children. One teacher commented “(When I don't like what is served), I don't eat anything. A lot of times I just go hungry. When I get off work I tend to overeat because I am so hungry. We don't have good choices at work." Teachers expressed concern over the meals being served, often describing the types of foods offered during meals as being of poor nutritional quality and/or limited in variety. These issues created challenges for teachers who were attempting to make healthy dietary choices for themselves.

\section{Physical setting}

Characteristics of the natural and built environment that reportedly impacted teachers' personal healthy eating and PA behaviors were identified as Environmental Supports and Environmental Barriers. Teachers described having access to resources (e.g. activity-based video games) and/or facilities (e.g. access to a gym or walking trail) where they could engage in PA, facilitated their ability to make healthy choices. However, barriers were also described such as daylight savings time and weather. 


\section{Teachers' professional experiences with advocating for healthy behavior and physical activity}

\section{Human aggregate}

Sociocultural characteristics that reportedly impacted teachers' ability to professionally promote healthy eating and PA behaviors among children and families were identified as Motivators to Promote Positive Health Behaviors and Perception of Role to Promote Positive Health Behaviors. All teachers described their genuine desire for children in their classroom to be healthy, feelings of making a difference and seeing children enjoy healthy foods as motivators for promoting positive health behaviors in their classrooms. Most teachers stated that they were also motivated to teach parents about positive health behaviors so that they can serve as role models to their children. Several teachers described feeling like they were "making a difference" helped motivate them to continue teaching children and parents about leading a healthy lifestyle. Most teachers agreed they felt an "obligation" or "responsibility to teach" children and families about making positive health behavior choices. Approximately half of the teachers described using children as an agent of change for their families by encouraging them to ask their parents to purchase healthy foods. However, other teachers expressed a helpless feeling related to their ability to successfully influence children and/or families health behaviors.

\section{Social climate}

Social characteristics that reportedly impacted teachers' ability to promote healthy eating and PA behaviors were categorized as Perceived Child-related Factors and Perceived Parent-related Factors. Child-related barriers included children's fear of trying new foods and children's disinterest in being physically active. All teachers described difficulty in trying to get children to try new foods citing limited prior exposure to healthy foods at home. However, most were able to describe strategies for overcoming these barriers such as using food-based learning experiences, utilizing menus and mealtimes for discussion about positive health behaviors, encouraging children 
to try new foods including the "one bite" rule, role modeling and integrating learning with other subjects (e.g. dental health). Teachers also described children not wanting to engage in physical activities during the day because they are "tired and want to sit down." A few teachers felt the lack of interest in PA among some children may have been due to being overweight. Teachers described strategies for encouraging children to be physically active as role modelling and using music.

Parents presented several social challenges including engagement, communication, and cultural and socioeconomic barriers. Some teachers described having difficulty promoting positive health behaviors to families due to lack of parent engagement. Reasons for limited parent engagement often included busy work schedules and/or family transportation challenges. Most teachers expressed concern over the limited communication they have with parents throughout the year. Some children ride a bus to and from school, meaning a teacher would have little to no contact with parents over the school year. These teachers also reported barriers to interacting with parents who drop-off or pick-up their children from school, stating they found it difficult to supervise children in their classroom while trying to hold meaningful conversations with parents about health behaviors.

Many teachers felt parents/families were unwilling to change their personal health behaviors at home because they are "set in their ways," referencing challenges related to cultural and/or generational influences. Teachers also felt that families' economic status presented greater challenges to making positive health choices, including limited time and/or energy to prepare meals at home and/or have sit down family meals. Teachers perceived parents were more likely to make poor dietary choices by purchasing quick foods (e.g. fast food) and/or giving children "bad food" that they like to eat out of convenience. Despite these challenges, teachers also described parent-focused strategies such as inviting parents to engage in healthy eating and PA opportunities at school (e.g. sharing a meal, family fun nights, attending a planned classroom activity), sending home information (e.g. flyers in backpacks, menus/recipes), participating in home visits and working to establish a strong rapport with parents in an effort to facilitate communication about healthy eating and physical activities. 


\section{Organizational setting}

Organizational characteristics that reportedly impacted teachers' professional healthy eating and PA advocacy behaviors were described as Administrative Support, Community Support and Policy \& Regulations. Teachers described administrative support in their programs as encouraging teacher-child play, including nutrition education and PA in their lesson plans, and providing healthy meals. However, some teachers discussed having limited time available to concentrate on nutrition education topics due to other instructional requirements. Community support came from local health professionals coming in to teach children about nutrition and PA and in the form of fruit/vegetable donations for food tastings. Finally, policies and regulations were cited as organizational characteristics that reportedly impacted teachers' efforts to promote positive health behaviors. Teachers described not being able to bring in outside food into the classroom and having a lack of control over the foods being served. Many teachers expressed dissatisfaction with the quality of meals served. One teacher commented, “We can't bring our own food to work; we have to eat what is served to us. Even though I try to promote it to the kids, I just don't like it."

\section{Physical setting}

Characteristics of the natural and built environment that reportedly impacted teachers' professional healthy eating and PA advocacy behaviors were described as Environmental Supports and Barriers. Teachers commonly described the weather as influencing the type and environment for PA. For example, a rainy day meant that children must engage in physical activities indoors $v$. outside. Some teachers discussed having access to indoor child-size exercise equipment that children could play on when the weather is not suitable; however, other teachers reported they did not have access to these types of resources. Finally, teachers reported parents often describe their home environments as being a barrier to engaging in healthy eating and PA. For example, when the weather is too hot or they do not have a place to exercise and/or play safely, it limits opportunities for PA. 
Making the connection between personal health experiences and professional health promotion

Finally, teachers described connections between their personal and professional experiences with healthy eating and PA. Connections directly acknowledge by teachers included Energy for my Students, Emphasizing for Better Health and Helpless to Help. Approximately half of the teachers made clear connections between their own health behaviors and classroom practices. These factors were only observed at the Human Aggregate level of the Theory of Social Ecology (Table 2). Several teachers described the importance of making positive dietary and PA choices so they would "have energy to keep up with my students." One teacher stated she had observed how eating poorly affected her physical health. This negative experience motivated her to promote healthy eating and PA among the children in her classroom because she did not want to see them "in the same type of situation." Many teachers also expressed a desire for children and families to be healthy so that they would not have to face the same challenges the teachers personally faced and described the FESSM as helpful towards achieving this goal. One teacher stated, "(FESSM has) helped me give information where it's needed to parents and even to coworkers. We still talk about our classes that we had. (It has helped us a lot) to get information to our parents. And we talk to our children about how healthy it is to eat good things."

Not all teachers made a connection between their health behaviors and their classroom practices. When asked directly about how participating in the FESSM intervention impacted their classroom practices, one teacher stated, “I don't think it has yet, I don't think more than I normally would do prior to taking the class." Similar statements were made by a small number of teachers. These teachers were more likely to state they felt parents had a greater influence on the children than they did, and often described how parents worked against their efforts by not engaging in health promotion activities offered by the teacher and or promoting negative health behaviors. Several teachers cited a helpless feeling when it came to encouraging children and families to change their health behaviors. Poor parent contact and communication throughout the year appeared to make this situation worse. 


\section{Discussion}

This study conducted a qualitative exploration of HS teachers' lived experiences with (1) trying to eat healthy and engage PA and (2) promote healthy eating and PA in their classrooms (Figure 1). Study findings provide unique insight into individual, social and environmental determinants that may influence teachers' health behaviors and health promotion practices after participating in a healthy eating and PA intervention. Further, the study explores the interrelationship between the personal and professional social ecological structures as directly acknowledge by teachers' themselves.

\section{Personal experiences with healthy eating and physical activity}

Teachers expressed a desire to make positive health choices, recognizing the impact their decisions had or would have on their health and their family members. Similarly, teachers described taking responsibility for their health and health behaviors and were motivated to learn how to improve them. ${ }^{2}$ Therefore, teachers were also eager to serve as positive role models for children in their immediate family. Unfortunately, while teachers' overall outlook towards making positive health choices were optimistic, prior research has indicated that they may need more support in this area as evidenced by limited personal nutrition knowledge and struggles with healthy eating. ${ }^{2,13}$

When compared with women from similar sociodemographic backgrounds, HS teachers are more likely to be overweight or obese, ${ }^{2,23}$ have higher rates of diabetes and high blood pressure, and poor mental health. ${ }^{27}$ While HS teachers may be motivated to serve as positive role models, their own health behaviors may first need improvement. ${ }^{\circ}$ Our findings add to the literature suggesting HS teachers are optimistic and motivated to make positive health choices; however, it is important to remember that teachers who participated in this study had recently completed the FESMM intervention. As a result, teachers may have felt more confident in their personal nutrition knowledge and may have been more motivated to make positive health choices at the time of their interview compared with teachers interviewed in prior studies.

For HS teachers, our findings suggest that social and environmental influences play an important role in their everyday personal health 
choices. For example, teachers often discussed the socio-economic barriers they faced when trying to make positive dietary and PA choices. Like the background of HS families, teachers are likely to be low income. ${ }^{2}$ In addition to modest pay, early childhood positions also often include limited benefits such as paid sick and vacation time. ${ }^{51,52}$ Teachers' shifts are frequently long and structured, often not allowing for the flexibility to meet personal needs such as seeking health care. ${ }^{53}$ These factors can lead to high absenteeism, employee turnover and burnout. ${ }^{51} \mathrm{~A}$ recent review of the health status of childcare workers further revealed teachers personally struggle with healthy eating, PA and mental health (stress and depression). ${ }^{52}$ Early childhood teachers reportedly face many additional barriers when it comes to making positive dietary and PA choices including being tired the end of the day, having limited time and numerous after-work responsibilities (e.g. caring for own child, preparing meals). ${ }^{53}$ Taken together, these challenges can serve as a roadblock for teachers intending to make positive health behavior choices, as well as their ability to effectively promote healthy eating among young children. ${ }^{10,54}$

Teachers also often described they were more successful when environmental supports were available to help support their choices to make positive health behaviors. For example, teachers described having support systems through family, friends or local community groups that helped them remain accountable and encouraged them continue making positive choices. A potential missed opportunity may be the use of the workplace setting to provide teachers with a prospect for both individual-level behavior and environmental change. Past research has demonstrated that dietary behaviors can be positively impacted through employee wellness programs that focus on education and healthful modifications in the work environment. ${ }^{55^{-61}} \mathrm{~A}$ few prior studies have explored the promising approach of employee wellness programs in the preschool setting $38,59,60$; however, findings are mixed. Esquivel and colleagues found positive results after implementing the Children's Health Living Program, a multi-component intervention that included an employee wellness component, in twenty-three HS classrooms (eleven intervention, twelve delayed intervention). Teachers reported improvements in PA levels, weight control, dietary behaviors, skills and knowledge about nutrition. ${ }^{38}$ However, Linnan and colleagues reported less promising outcomes for Caring and Reaching 
for Health (CARE), a multi-level, theory-guided intervention designed to improve early childhood teachers' PA (main outcome) and several other health behaviors (e.g. diet, stress). The intervention was not successful at improving teachers' PA levels, but researchers did observe significant improvements in dietary outcomes (e.g. fruits and vegetables, sugar sweetened beverages). These significant differences were no longer observed after controlling for multiple comparisons. In post-interviews with teachers, participants expressed a desire for more personal or "high-touch" interactions including more personal communication such as text messaging and in-person events with coworkers and/or research staff. 39

Utilizing employee wellness programs within HS programs may be a chance to effectively create the culture of health teachers in the current study described as being an important facilitator of their choice to personally practice and professionally advocate for positive health behaviors. However, more research is needed to explore the efficacy of implementing a wellness program in the HS setting, including evaluation of the National Head Start Association's Nurturing Staff Wellness toolkit, a seven-step guide designed for HS programs interested in implementing a wellness program. ${ }^{60}$ Future research should also identify and reduce organizational and environmental barriers to change, address social contextual factors that drive behaviors and build expanded networks of community partnerships that may be supportive of employee wellness programming. ${ }^{19,55}$

\section{Professional experiences promoting healthy eating and physical activity behaviors among children and families}

Teachers in our study reported that they had a responsibility to provide education about healthy eating and PA to the children and families they serve. Similar findings have been observed in other studies with preschool teachers reportedly perceiving themselves as "parents at school" and expressing a desire to positively impact children's current and future well-being. ${ }^{14,62-64}$ Recognizing children as potential agents of change, current study teachers often reported that they encouraged children to ask parents about buying healthy foods or doing physical activities at home. All teachers described challenges with getting children to try new foods. Preschool children's willingness to try new foods is impacted by several factors including neophobia 
("unwillingness to eat novel foods") and pickiness; both are common among preschool-aged children. ${ }^{65}$ Interestingly, teachers in the current study were able to describe several evidence-based strategies for overcoming this challenge indicating they felt prepared to address the issue when it arose in their classroom.

Like the findings of Derscheid, ${ }^{16} \mathrm{Ajja}{ }^{66}$ and Swindle, ${ }^{14}$ teachers also often described menus as a barrier to health promotion in their classroom. Teachers expressed a lack of control over menu items served. Teachers reported food items featured on menus not only impacted their ability to promote healthy foods provided during meals and snacks but also inhibited their ability to make healthy dietary choices themselves. Swindle \& Phelps ${ }^{67}$ interviewed twenty-eight early childhood teachers (fifteen were employed in HS centers) who also described the foods served during mealtime as unhealthy and/or foods they did not enjoy. These teachers reported using coping skills such as pretending to eat, telling children their physician told them not to eat the food, cutting food into smaller pieces and allowing food to sit in front of them without eating it.

Federal Performance Standards require HS programs to participate in either the CACFP or the National School Lunch Program. ${ }^{8,68,69}$ Andreyeva and colleagues ${ }^{70}$ found that CACFP participating centers demonstrated more positive outcomes related to teacher behavior during meals (e.g. role modelling, creating a positive mealtime environment), ${ }^{23,69}$ nutritional characteristics of foods served and quality of children's dietary intake at school. However, our study findings and others ${ }^{20,71,72}$ suggest HS programs should consider teacher food preferences and/or teacher participation in the menu planning process as strategy for ensuring promotion of healthy foods served during meals and snacks. Owing to the recent (October 2017) national implementation of the updated CACFP meal pattern requirements, additional studies are needed to determine teachers' perspectives about trying foods based on the updated requirements. Understanding these issues is critical as teachers may be more likely to serve as positive role models for children in the mealtime setting when foods are "healthy and appealing." 67

Making the issue more complicated, HS PPS requires teachers to be served the same foods as children during mealtimes ( $45 \mathrm{CFE}$ 1304.23vii). Prior research has indicated HS teachers not only have 
lower quality diets but also experience higher rates of food insecurity. HS is currently the only early childhood program type in the United States that also consistently provides teachers with daily meals and snacks. ${ }^{14}$ Researchers have theorized that this policy may be an opportunity to improve dietary quality and food insecurity among HS teachers. ${ }^{73}$ However, teachers in our study reported not eating at all throughout the day due to "poor quality" meals (HS policy also prevents them from bringing in outside food), later causing them to overeat. It is unclear whether teacher dissatisfaction with meals being served in the HS center was related to teacher food preferences, actual poor nutritionally quality of food being served or a mix of both. Regardless, if teachers are consuming less due to these factors, poor quality menus could do more harm than good towards improving teachers' health behaviors and decreasing rates of food insecurity.

A Health/Nutrition Manager is generally responsible for developing school menus in HS programs. This individual does not have to be a Registered Dietitian/Nutritionist (RDN) or have a nutrition background, but they must "seek consultation from an RDN or nutritionist" (8 CFE 1302.91iii) for program support. The degree to which an RDN provides input on the quality of meals served likely varies by HS program. More research is needed to understand the role of RDN in this capacity, the magnitude of HS programs who utilize their services and what additional benefits they may be able to provide programs. CACFP training resources focused on menu development are available for HS program administrators and teachers at state and federal levels ${ }^{74,75}$; however, the extent to which this training is attended, who attends the training and how lessons learned are implemented into menus need further exploration. One study reported $<24 \%$ of staff from CACFP-funded centers attended yearly professional development, ${ }^{76}$ while other studies reported $68 \%$ and $92 \%$ of programs provide for staff about nutrition, respectively. ${ }^{26,77}$

Finally, teachers reported parent-related challenges, particularly regarding engagement, communication and socio-economic challenges. Prior research has indicated parental influence on children's behavior is critical. ${ }^{78,79}$ For this reason, parent engagement is a primary focus in HS. ${ }^{80}$ Federal Program Performance Standards require HS programs support family engagement in children's learning and development through parent-child activities, parent education, family goal setting 
and more ${ }^{81} \mathrm{HS}$ programs decide locally on how parent engagement will occur. Some programs may require teachers to do home visits or attend parent meetings, while others do not. The later approach may leave little opportunity for teacher-parent interaction. Similar to findings from Sisson et al., teachers in the current study also expressed concern about the socio-economic status of families and the potential impact on children's access to healthy foods. ${ }^{13}$ Like another study, ${ }^{82}$ teachers reported sending materials home for parents to read but noted that they do not know if parents receive and/or read these materials. Expert recommendations encourage teacher engagement with parents in promoting positive health behaviors; however, teachers in the current study and others described barriers to promoting positive health behaviors among families when communication channels were related to indirect communication (e.g. handouts) $v$. direct communication (e.g. in-person meetings, workshops). ${ }^{10,19,82-87}$ Past studies have also implied teachers may also struggle to communicate information to families about healthy eating and PA due to inadequate personal knowledge and training in the area, ${ }^{12,31-34,88}$ or a fear of offending parents. ${ }^{34}$

Further complicating the issue, our study findings also suggest that the level of interaction a teacher has with parents throughout the course of the year is highly variable. This outcome is concerning as teachers in our study and one other have described parent engagement as an important source of teacher motivation. Sisson et al. reported teacher motivation waned and levels of frustration increased when parent support is limited. ${ }^{13}$ Effective strategies supportive parent-teacher interaction, and communication is needed in order to improve the promotion of healthy eating among young children. ${ }^{89} \mathrm{HS}$ teachers may need additional support from staff focused on family engagement to develop strong partnerships with families, ${ }^{12,88}$ and training focused on communication skills to ensure messages about diet and PA are communicated to families. ${ }^{13,21}$ Health promotion programs in HS using teachers should carefully consider these challenges and design evidence-based strategies to improve teacher-parent interaction and relationship building. ${ }^{82,86,90}$ 


\section{Making the connection between personal health experiences and professional health promotion}

A unique aspect of this study was the ability to look across teachers' personal and professional experiences with healthy eating and PA. Interestingly, many teachers clearly made connections between their personal and professional experience with healthy eating and PA at the Human Aggregate. Similar to Lebron et al., ${ }^{21}$ teachers described the importance of role modelling healthy behaviors for the children in their classroom after receiving an intervention focused on improving their personal health behaviors. While not explicitly acknowledged by teachers, looking across the data, additional connections can be observed across the Social Climate, Organizational Setting and Physical Setting levels. For example, teachers described several personal barriers (social temptations, weather, time) and supports (people, social media, resources and facilities to support exercise, opportunities to learn) that were helpful towards supporting their ability to make positive dietary and PA choices. Studies have shown parents of preschool children share many of these same barriers and supports. ${ }^{88,91}$

Professionally, teachers also described barriers to engaging children in healthy eating and PA such as poor quality meals, weather and limited facilities/resources for PA. Teachers described poor quality school meals as negatively impacting their ability to eat healthy during the school day. Improvements in school meals may work to improve teachers dietary intake and food insecurity. ${ }^{14}$ Engaging teachers in the development of menus may help them feel supported by administration in their efforts to make positive dietary choices, while also supporting their ability to create positive mealtime environments and role model eating healthy foods. As previously mentioned, studies have also reported that early childhood teachers may spend a large portion of the day engaging in sedentary activities. ${ }^{17,18}$ Teachers may not take advantage of opportunities to engage in PA when they arise. Instead of engaging in PA along with children when playing outside, Sisson et al. reported teachers instead viewed this time as an opportunity to take a break or socialize with other teachers. Researchers theorized this was a potential barrier for role modelling. ${ }^{13}$ These factors demonstrate that environmental factors in the childcare setting may influence teachers' behaviors. It may be useful to provide teachers with 
training on how to advocate for healthy meal options and how to engage children in PA (indoors and outdoors) throughout the day while also helping the teacher to eat healthy and remain physically activity.

\section{Limitations and strengths}

The current study had limitations and strengths that should be acknowledged. Considering the qualitative nature and limited geographic scope of the study, findings may not be generalized to other HS teachers. Teachers in this study were $100 \%$ female and primarily African American, demonstrating limited gender and ethnic diversity among the perspectives expressed. Additionally, recruitment was limited to teachers who had recently completed the FESMM intervention. The views of these individuals may be different from other HS teachers, even within eastern NC. With this being said, demographics are similar to those reported by other studies of HS teachers employed in NC. 35,62,92 Future research should explore individual, social and environmental influences of teachers' health behaviors in more diverse populations (e.g. gender, ethnicity, type of early child and education care setting) and geographic locations. Semi-structured interviews following completion of the FESMM completion could be subject to social desirability bias. Some of the topics discussed in the interviews were sensitive in nature and may have resulted in skewed participant responses regarding their personal and professional experiences. Additionally, participants may have felt socially obligated to provide positive responses after being provided the opportunity to engage in FESMM. To reduce the likelihood of this outcome, none of the individuals who delivered the FESSM interventions were involved with data collection. To decrease the likelihood of this limitation, interviewers were trained to minimize this type of bias by remaining open to teachers' perspectives by remaining unbiased and nonjudgmental. ${ }^{6}$ It is important to recognize that the interviews in the current study were conducted prior to implementation of CACFP changes in 2017. It is possible teacher perceptions related to school meals have changed as result of these improvements and the passage of time. Finally, the primary theme of "Making the Connection" was emergent from the data. As an unexpected phenomenon, limited questions were asked in the interview guide that promoted teachers to directly reflect on their perceptions of interrelationships they see between their 
personal and professional experiences with healthy eating and PA. Future research should explore the interrelationship between teachers' personal health behaviors and their health promotion practices in the classroom. The study also had many strengths. Researchers used a rigorous approach in the data collection and analysis, including stakeholder engagement to inform the study protocols, pilot testing the interview guide, strong methods of trustworthiness, a standardized approach to training interviewers and coders ${ }^{46}$, drawing from a sample of teachers who all experienced the same intervention focused on improving their healthy eating and PA behaviors.

\section{Conclusion}

This study highlights the importance of considering personal and professional determinants of health when working with early childhood teachers. To the author's knowledge, it is one of the first studies to explore both teachers' experiences with their personal health and their health promotion practices in the classroom allowing researchers to observe where the two worlds intersect. Understanding how teachers view their personal health behaviors in relation to their role as a teacher to promote healthy behaviors may help researchers identify opportunities for strengthening interventions to promote teacher health and consequently children's healthful behaviors. ${ }^{16}$

Teachers want to improve health behaviors personally and professionally; however, well-described barriers exist at all levels influencing their ability to improve their own health and facilitate positive behaviors among the children/families they serve. Findings from the current study and others suggest that the early childhood setting itself may make it difficult for teachers to improve their personal health behaviors (e.g. poor quality meals, limited PA throughout the day), which may later impact teachers' professional practice through role modelling and child/parent education efforts. Administrators and teachers should be provided with professional development on how to implement policy and best practices in healthy eating and PA that are also supportive of teachers' personal health goals, as well as the children and families served. More research is also needed to understand influential contextual factors (e.g. background, prior experiences, personality types, attitudes, values) among teachers who have positive 
$v$. negative views about their ability to make an impact on the health behaviors of the children and families they serve.

Many prevention/intervention efforts are founded on the assumption that increasing knowledge and awareness among providers will result in positive behavior changes in the classroom. However, findings from the current study and others suggest researchers should not assume that providing teachers with healthy eating and PA education is enough to build their efficacy to pass on that knowledge and experience to children and families. ${ }^{22,29,93}$ Some teachers may need more support in understanding the connection between their personal and professional experiences, recognizing opportunities to advocate for healthy eating and engage in PA throughout the day, and support families in their efforts to make positive health choices. Finally, if we desire teachers to help families make actual behavior changes, professional development in creating strong teachers-parent partnerships around healthy eating and PA topics may also needed. If a teacher perceives it to be her responsibility to get families to change their behaviors, and fails, this could augment feelings of discouragement and helplessness reported by some teachers in the current study and others (Sisson et al., 2017) ${ }^{13,62}$.

The success of obesity prevention programs in the HS setting is dependent on teachers embracing and implementing developed programming into their classrooms. ${ }^{11}$ As researchers and interventionists, we should be clear about teachers' role expectations (e.g. education or helping make behavior changes) and provide professional development accordingly. ${ }^{19}$ Teachers with limited nutrition background are unlikely to implement and support effective healthy eating and PA programming in childcare settings without additional support. ${ }^{44}$ Teaching teachers how to promote healthy eating and PA may help them serve as more positive role models for children and parents and strengthen teachers' ability to promote healthy behaviors ${ }^{19}$; however, more research is needed to fully understand the impact of teachers' personal health behaviors on the strategies they use to promote health in their classrooms. Understanding the determinants of health that influence their personal and professional experiences with healthy eating and $\mathrm{PA}$ and the connections between is a step in that direction. 
Acknowledgments The authors would like to thank the HS centers and teachers who participated in the study. Additionally, the authors thank the research staff who supported the data collection process: Faiza Mustafa, Kristina Bandy and Joshua Butler. Permission was requested and granted from all persons acknowledged. Financial support: This work was supported by the East Carolina University Engagement of Scholarship Academy. East Carolina University Engagement of Scholarship Academy had no role in the design analysis or writing of this article.

Conflict of interest There are no conflicts of interest.

Authorship V.C.S. conceived the study, took lead in its design, conduct, coordination and data collection. L.S.G. and L.J. supported the study design by reviewing protocols and the interview guide. V.C.S. and J.B. led the qualitative analyses. V.C.S. led the alignment of themes and subthemes with the Theory of Social Ecology with support and feedback from J.B., L.S.G., D.D. and V.C.S. led the writing of the manuscript while D.D., L.J., A.H., J.B. and L.S.G. contributed editing of the entire paper. All authors contributed to the interpretation of data and read and approved the final manuscript.

Ethics of human subject participation The study was conducted according to the guidelines laid down in the Declaration of Helsinki, and all procedures involving research study participants were approved by the East Carolina University Institutional Review Board. Written informed consent was obtained from all subjects.

\section{References}

1. US Department of Health and Human Services Administration for Children and Families (2020) About the Office of Head Start. https://www.acf.hhs.gov/ohs/about (accessed October 2020).

2. Sharma S, Dortch KS, Byrd-Williams C et al. (2013) Nutrition-related knowledge, attitudes, and dietary behaviors among Head Start teachers in Texas: a cross-sectional study. J Acad Nutr Diet 113, 558-562.

3. National Head Start Association (2019) National Head Start Fact Sheet. https://www.nhsa. org/national-head-start-factsheets (accessed October 2019).

4. Tarullo L, West J, Aikens N et al. (2008) Beginning Head Start: children, families and programs in fall 2006. Mathematica Policy Research, Inc; available at https://www.acf.hhs. gov/sites/default/files/opre/beginning hs.pdf (accessed September 2019).

5. Lumeng JC, Kaciroti N, Sturza J et al. (2015) Changes in Body Mass Index associated with Head Start participation. Pediatrics 135, e449-e456.

6. Zigler E, Piotrkowski CS \& Collins R (1994) Health services in head start. Annu Rev Public Health 15, 511-534.

7. Ritchie LD, Boyle M, Chandran K et al. (2012) Participation in the Child and Adult Care Food Program is associated with more nutritious foods and beverages in child care. Child Obes 8 , 224-229. 
8. Whitaker RC, Gooze RA, Hughes CC et al. (2013) A national survey of obesity prevention practices in Head Start. Arch Pediatr Adolesc Med 163, 1144-1150.

9. Dev D \& McBride B (2013) Academy of Nutrition and Dietetics benchmarks for nutrition in child care 2011: are child-care providers across contexts meeting recommendations? J Acad Nutr Diet 113, 1346-1353.

10. Benjamin-Neelon SE (2018) Position of the Academy of Nutrition and Dietetics: benchmarks for nutrition in child care. J Acad Nutr Diet 118, 1291-1300.

11. Lumeng JC, Kaplan-Sanoff M, Shuman S et al. (2007) Head Start teachers' perceptions of children's eating behavior and weight status in the context of food scarcity. J Nutr Educ Behav 40, 237-243.

12. Lynch M \& Batal M (2011) Factors influencing childcare providers' food and mealtime decisions: an ecological approach. Child Care Pract 17, 185-203.

13. Sisson SB, Smith CL \& Cheney M (2017) Big impact on small children: child-care providers' perceptions of their role in early childhood healthy lifestyle behaviors. Child Care Pract 23, 162-180.

14. Swindle TM, Ward WL, Bokony P et al. (2018) A cross-sectional study of early childhood educators' childhood and current food insecurity and dietary intake. J Hunger Environ Nutr 13, 40-54.

15. Larsen JK, Hermans RC, Sleddens EF et al. (2015) How parental dietary behavior and food parenting practices affect 3474 VC Stage et al. children's dietary behavior. Interacting sources of influence? Appetite 89, 246-257.

16. Song WO, Song S, Nieves V et al. (2016) Nutritional health attitudes and behaviors and their associations with the risk of overweight/obesity among child care providers in Michigan Migrant and Seasonal Head Start centers. BMC Public Health 16, 648.

17. Shen D, Mao W, Liu T et al. (2014) Sedentary behavior and incident cancer: a meta-analysis of prospective studies. PLoS One 9, e105709.

18. Thorp AA, Owen N, Neuhaus M et al. (2011) Sedentary behaviors and subsequent health outcomes in adults: a systematic review of longitudinal studies, 1996-2011. Am J Prev Med 41, 207-215.

19. Hughes CC, Gooze RA, Finkelstein DM et al. (2009) Barriers to obesity prevention in Head Start. Health Aff 29, 454-462.

20. Derscheid LE, Umoren J, Kim S et al. (2010) Early childhood teachers' and staff members' perception of nutrition and physical activity preferences for preschoolers. J Res Child Educ 24, 248-265.

21. Lebron CN, Ofori A, Sardinas K et al. (2020) Barriers and facilitators to obesity prevention dissemination and implementation efforts in the childcare centre setting from the provider perspective. Child Care Health Dev 46, 352-369.

22. Lanigan JD (2012) The relationship between practices and child care providers' beliefs related to child feeding and obesity prevention. J Nutr Educ Behav 44, 521-529.

23. Dev DA, Speirs KE, McBride BA et al. (2014) Head start and child care providers' motivators, barriers, and facilitators to practicing family style meal service. Early Child Res Qtly 29, 649-659.

24. Ward S, Blanger M, Donovan D et al. (2017) Association between childcare educators' practices and preschoolers' physical activity and dietary intake: a cross-sectional analysis. BMJ Open 7, 1-8.

25. Dev DA, McBride BA, Speirs KE et al. (2014) Predictors of head start and child-care providers' healthful and controlling feeding practices with children aged 2-5 years. J Acad Nutr Diet 114, 1396-1403. 
26. Halloran KM, Gorman K, Fallon M et al. (2018) Nutrition knowledge, attitudes, and fruit and vegetable intake as predictors of Head Start Teachers' classroom mealtime behaviors. J Nutr Educ Behav 50, 340-348.

27. Whitaker R, Becker B, Herman A et al. (2013) The physical and mental health of Head Start staff: the Pennsylvania Head Start staff wellness survey, 2012. Prev Chron Dis 10, E181.

28. Nahikian-Nelms M (1997) Influential factors of caregiver behavior at mealtime: a study of 24 childcare programs. J Am Diet Assoc 97, 505-509.

29. Freedman MR \& Alvarez KP (2010) Early childhood feeding: assessing knowledge, attitude, and practices of multi-ethnic child-care providers. J Am Diet Assoc 110, 447-451.

30. Fees B, Trost S, Bopp M et al. (2009) Physical activity programming in family child care homes: providers' perceptions of practices and barriers. J Nutr Educ Behav 41, 268-273.

31. Lindsay AC, Salkeld JA, Greaney ML et al. (2015) Latino family childcare providers' beliefs, attitudes, and practices related to promotion of healthy behaviors among preschool children: a qualitative study. J Obes 2015, 1-9.

32. Lyn R, Evers S, Davis J et al. (2014) Barriers and supports to implementing a nutrition and physical activity intervention in child care: directors' perspectives. J Nutr Educ Behav 46, 171-180.

33. Rosenthal MS, Crowley AA \& Curry L (2013) Family child care providers' self-perceived role in obesity prevention: working with children, parents, and external influences. J Nutr Educ Behav 45, 595-601.

34. Taveras EM, LaPelle N, Gupta RS et al. (2006) Planning for health promotion in low-income preschool child care settings: focus groups of parents and child care providers. Ambul Pediatr 6, 342-346.

35. Carraway-Stage VC, Henson SR, Dipper A et al. (2014) Understanding the state of nutrition education in the Head Start classroom: a qualitative approach. Am J Health Educ 45, 52-62.

36. Peterson A, Goodell S, Hegde A et al. (2017) Teacher perceptions of multilevel policies and the influence on nutrition education in North Carolina Head Start Preschools. J Nutr Educ Behav 49, 387-396.

37. Lisson S, Goodell S, Dev D et al. (2016) Nutrition Education Resources in North Carolinabased Head Start Preschool Programs: administrator and teacher perceptions of availability and use. J Nutr Educ Behav 48, 655-663.

38. Esquivel MK, Nigg CR, Fialkowski MK et al. (2016) Influence of teachers' personal health behaviors on operationalizing obesity prevention policy in Head Start preschools: a project of the children's health living program. J Nutr Educ Behav 48, 318-325.

39. Linnan LA, Vaughn AE, Smith F et al. (2020) Results of Caring and Reaching for Health (CARE): a cluster-randomized controlled trial assessing a worksite wellness intervention for child care staff. Int J Behav Nutr Phys Act 17, 64 .

40. Tovar A, Mena NZ, Risica P et al. (2015) Nutrition and physical activity environments of home-based child care: what Hispanic providers have to say. Child Obes 11, 521-529.

41. Mita SC, Gray SA \& Goodell LS (2015) An explanatory framework of teachers' perceptions of a positive mealtime environment in a preschool setting. Appetite 90, 37-44.

42. Jones L, McDonald S \& Stage VC (2018) Eating Smart and Moving More for Head Start: Teaching Guide, 1st ed. NC State Extension Expanded Food and Nutrition Education Program.

43. Jones L, Dunn C, Foley E et al. (2016) Families Eating Smart and Moving More, 3rd ed. NC: State Extension Expanded Food and Nutrition Education Program.

44. Moustakas C (1994) Phenomenological Research Methods. Thousand Oaks: Sage. 
45. Creswell JW (2012) Educational Research: Planning, Conducting, and Evaluating Quantitative and Qualitative Research, 4th ed. Boston: Pearson.

46. Hall E, Chai W \& Albrecht JA (2016) A qualitative phenomenological exploration of teachers' experience with nutrition education. Am J Health Educ 47, 136-148.

47. Goodell LS, Stage VC \& Cooke NK (2016) Practical qualitative research strategies: training interviewers and coders. J Nutr Educ Behav 48, 578-585.

48. Bowen GA (2008) Naturalistic inquiry and the saturation concept: a research note. Qual Res $8,132-152$.

49. Shenton A (2004) Strategies for ensuring trustworthiness in qualitative research projects. Educ Inf 22, 63-75.

50. Moos RH (1980) Social-ecological perspectives on health. In Health Psychology: A Handbook [F Cohen \& NE Adler, editors]. San Francisco: Jossey-Bass.

51. Ward DS, Vaughn A \& Story M(2013) Expert and stakeholder consensus on priorities for obesity prevention research in early care and education settings. Child Obes 9, 116-124.

52. Carson RL, Baumgartner JJ, Matthews RA et al. (2010) Emotional exhaustion, absenteeism, and turnover intentions in childcare teachers: examining the impact of physical activity behaviors. J Health Psychol 15, 905-914.

53. Lessard LM, Wilkins K, Rose-Malm J et al. (2020) The health status of the early care and education workforce in the USA: a scoping review of the evidence and current practice. Public Health Rev 41, 1-17.

54. Child Care Aware of America (2012) Paths to a healthier child care workforce. http://usa. childcareaware.org/wp-content/uploads/2017/03/Staff-wellness-white-paper.pdf (accessed February 2020).

55. Whitaker RC, Dearth-Wesley T \& Gooze RA (2015) Workplace stress and the quality of teacher-children Head Start Teachers' experiences with health 3475 relationships in Head Start. Early Child Res Qtly 30, 57-69.

56. Story M, Kaphingst KM, Robinson-O'Brien R et al. (2008) Creating healthy food and eating environments: policy and environmental approaches. Annu Rev Public Health 29, 253-272.

57. Biener L, Glanz K, McLerran D et al. (1999) Impact of the working well trial on the worksite smoking and nutrition environment. Health Educ Behav 26, 478-494.

58. Engbers LH, van Poppel MN, Chin APMJ et al. (2005) Worksite health promotion programs with environmental changes: a systematic review. Am J Prev Med 29, 61-70.

59. Sorensen G, Linnan L \& Hunt MK (2004) Worksite-based research and initiatives to increase fruit and vegetable consumption. Prev Med 39, S94-S10o.

6o. Gosliner WA, James P, Yancey AK et al. (2010) Impact of a worksite wellness program on the nutrition and physical activity environment of child care centers. Am J Health Promot 24, 186-189.

61. Tamers SL, Beresford SAA, Cheadle AD et al. (2011) The association between worksite social support, diet, physical activity, and body mass index. Prev Med 53, 53-56.

62. National Head Start Association (2017) Nurturing Staff Wellness. Alexandria: National Head Start Association; available at https://www.nhsa.org/nurturing-staff-wellness (accessed February 2020).

63. Mita SC, Li E \& Goodell LS (2013) A qualitative investigation of teachers' information, motivation, and behavioral skills for increasing fruit and vegetable consumption in preschoolers. J Nutr Educ Behav 4, 793-799.

64. Tucker P, Irwin JD, He M et al. (2006) Preschoolers' dietary behaviors: parents' perspectives. Can J Diet Pract Res 67, 67-71. 
65. Shriver LH, Hildebrand D \& Austin H (2010) Determinants of fruit and vegetable availability in Hispanic Head Start families with preschool-aged children living in an urban midwestern area. J Nutr Educ Behav 42, 299-306.

66. Galloway AT, Lee Y \& Birch LL (2003) Predictors and consequences of food neophobia and pickiness in young girls. J Am Diet Assoc 103, 692-698.

67. Ajja R, Beets MW, Chandler J et al. (2015) Physical activity and healthy eating environmental audit tools in youth care settings: a systematic review. Prev Med 77, 80-98.

68. Swindle T \& Phelps J (2018) How does context relate to nutrition promotion and mealtime practice in early care and education settings? A qualitative exploration. J Acad Nutr Diet 118, 2081-2093.

69. U.S. Department of Health and Human Services, Administration for Children and Families (2016) Head Start Performance standards. Final rule. Fed Regist 81, 61294-61453.

70. Swindle TM, Patterson Z \& Boden CJ (2017) A qualitative application of the Belsky Model to explore early care and education teachers' mealtime history, beliefs, and interactions. $J$ Nutr Educ Behav 49, 568-578.

71. Andreyeva T, Kenney EL, O'Connel M, et al. (2017) Predictors of nutrition quality in early childhood education settings in Connecticut. J Nutr Educ Behav 50, 458-467.

72. Dev DA, McBride B, \& The STRONG Kids Research Team (2013) Academy of Nutrition and Dietetics Benchmarks for nutrition in child care 2011: are child-care providers across contexts meeting recommendations? J Acad Nutr Diet 113, 1346-1353.

73. Markides BR, Crixell SH, Thompson C et al. (2017) Staff workshop improves child care menus in south central Texas: a Best Food for Families, Infants, and Toddlers (Best Food FITS) intervention. J Nutr Educ Behav 49, 435-440.

74. Loth KA, MacLehose RF, Fulkerson JA et al. (2014) Are food restriction and pressure-to-eat parenting practices associated with adolescent disordered eating behaviors? Int J Eat Disord 47, 310-314.

75. Nemours Children's Health System CACFP New Meal Pattern Guidelines and Resources (2020). https://healthykidshealthyfuture.org/cacfp/ (accessed October 2020).

76. Head Start Fully Implementing the New CACFP Meal Patters: Tips and Strategies for Success (2020). https://eclkc.ohs.acf.hhs.gov/video/fully-implementing-new-cacfp-mealpatternstips-strategies-success (accessed October 2020).

77. Signman-Grant M, Christiansen E, Fernandez G et al. (2011) Child care training and a supportive feeding environment in child care settings in 4 states, 2003. Prev Chron Dis 8, 1-11.

78. Gooze RA, Hughes CC, Finkelstein DM et al. (2010) Reaching staff, parents, and community partners to prevent childhood obesity in Head Start, 2008. Prev Chron Dis 7, 1-9.

79. Alkon A, Crowley AA, Neelon SE et al. (2014) Nutrition and physical activity randomized control trial in child care centers improve knowledge, policies, and children's body mass index. BMC Public Health 14, 215.

80. Dwyer G, Higgs J, Hardy LL et al. (2008) What do parents and preschool staff tell us about young children's physical activity: a qualitative study. Int J Behav Nutr Phys Act 5, 66.

81. Spinks AB, Macpherson AK, Bain C et al. (2007) Compliance with the Australian national physical activity guidelines for children: relationship to overweight status. J Sci Med Sport 10, 156-163.

82. Early Childhood Learning \& Knowledge Center (2019) Early Childhood Learning \& Knowledge Center: Family engagement. https://eclkc.ohs.acf.hhs.gov/family-engagement (accessed September 2019). 
83. Dev DA, Byrd-Williams C, Ramsay S et al. (2017) Engaging parents to promote children's nutrition and health: providers' barriers and strategies in Head Start and child care centers. Am J Health Promot 31, 153-162.

84. Head Start (2019) Head Start performance standards: final rule. Fed Regist 81, 61294-61453.

85. Larson N, Loth KA \& Nanney MS (2018) Staff training interests, barriers, and preferences in rural and urban child care programs in Minnesota. J Nutr Educ Behav 51, 335-341.

86. Foster J, Contreras D, Gold A et al. (2015) Evaluation of nutrition and physical activity policies and practices in child care centers within rural communities. Child Obes 11, 506-512.

87. Trost S, Messner L, Fitzgerald K et al. (2009) Nutrition and physical activity policies and practices in family child care homes. Am J Prev Med 37, 537-540.

88. Tucker P, van Zandvoort MM, Burke SM et al. (2011) The influence of parents and the home environment on preschoolers' physical activity behaviors: a qualitative investigation of childcare providers' perspectives. BMC Public Health 11, 240.

89. Johnson SL, Ramsay S, Shultz JA et al. (2013) Creating potential for common ground and communication between early childhood program staff and parents about young children's eating. J Nutr Educ Behav 45, 558-570.

90. Ross SET, Macia L, Documet PI et al. (2018) Latino parents' perceptions of physical activity and healthy eating: at the intersection of culture, family, and health. J Nutr Educ Behav 50, 968-976.

91. Ling J, Robbins LB \& Hines-Martin V (2016) Perceived parental barriers to and strategies for supporting physical activity and healthy eating among Head Start children. J Comm Health 41, 593-602.

92. Stage VC, Wilkerson K, Hegde A et al. (2018) Head Start administrator and teacher perceptions of parental influence on children's nutrition education. J Early Child Res 16, 16o-175.

93. Erinosho T, Vaughn A, Hales D et al. (2018) The quality of nutrition and physical activity environments of child-care centers across three states in the southern US. Prev Med 113, 95-101.

94. Dunn CG, Burgermaster M, Adams A et al. (2019) A systematic review and content analysis of classroom teacher professional development in nutrition education programs. Adv Nutr 10, 351-359. 